\title{
Özel Eğitim Öğretmenlerinin Sosyal Problem Çözme Becerilerinin Değerlendirilmesi
}

\author{
Evaluation of Social Problem-Solving Skills of Special Education Teachers
}

\section{Deniz TEKINN ERSAN* Şükran ALAN**}

Öz: Bu araştırmanın amacı özel eğitim öğretmenlerinin sosyal problem çözme becerilerinin düzeylerinin belirlenmesidir. Özel eğitim öğretmenlerinin problem çözme becerileri cinsiyet ve çalışma yllı değişkenlerine göre incelenmiştir. Araştırmaya çeşitli illerde görev yapmakta olan 115 özel eğitim öğretmeni katılmıştır. Araştırma verileri, araştırmacılar tarafından hazırlanan demografik form, sosyal problem çözme becerileri için D' Zurilla ve diğerleri (2002) tarafından geliştirilen ve Çekici (2009) tarafından Türkçeye uyarlanan "Sosyal Problem Çözme Envanteri- Kısa Formu”, kullanılmıştır. Verilerin yüzde ve frekans dökümleri alınmış ve t- testi uygulanmıştır. Araştırma bulgularına göre, öğretmenlerin cinsiyete göre sosyal problem çözme özellikleri incelendiğinde; kadın öğretmenlerin daha fazla olumsuz yönelim, erkek öğretmenlerin ise daha fazla kaçınım gösterdiği bulunmuştur. Çalışma yılına göre ise sosyal problem çözme özelliklerinde anlamlı fark bulunmamıştır.

Anahtar sözcükler: Özel Eğitim, Özel Eğitim Öğretmenleri, Problem Çözme Becerileri, Sosyal Problem Çözme

Abstract: The purpose of this study was to investigate the social problem-solving skill levels of special education teachers in terms of gender and seniority variables. 115 special education teachers who work in different provinces participated in this study. For demographic data, a form which was developed by researchers was used. In order to collect social problem-solving skill levels data, the Social ProblemSolving Inventory-Short Form which was developed by D' Zurilla et al. (2002) and adapted to Turkish by Çekici (2009) was used. According to finds from this study, female teachers reveal more negative orientation to the problems and male teachers reveal more avoidance. In terms of seniority, there is no significant difference.

Keywords: Problem Solving Skills, Social Problem Solving, Special Education Teachers, Special Education

Modern yaşam, devinim halinde karmaşık yapıları ve sürekli değişimi hayatımıza getirmiştir. $\mathrm{Bu}$ sebeple kişilerin baş etmesi gereken durumlar ve engeller de karmaşıklaşmış ve kişilerin daha etkili çözümler üretmesi gerekliliği oluşmuştur (Heppner, Witty \& Dixon 2004). Böylelikle, problem çözme ve günlük yaşamda gerçekleşen sosyal problem çözme üzerine çalışılmaya başlanmıştır.

Alan yazında problem ve problem çözmeyle ilgili farklı tanımlar bulunmaktadır. Dewey problemi, insan zihnini karıştıran, ona meydan okuyan ve inancı belirsizleştiren her şey olarak

\footnotetext{
*Yrd. Doç. Dr., Muğla Sıtkı Koçman Üniversitesi, Eğitim Fakültesi, Özel Eğitim Bölümü, Muğla. deniztekinersan@mu.edu.tr

** Arş. Gör., Anadolu Üniversitesi, Eğitim Fakültesi, Özel Eğitim Bölümü, Eskişehir. sukranalan@anadolu.edu.tr
} 
tanımlamıştır (Gelbal 1991). Problem, bireyin yaşadığı anda içinde bulunduğu hali ile olmasını arzu ettiği hal arasındaki ayrım olarak da ifade edilebilir (Chang, D'Zurilla \& Sanna 2004). Problem çözme ise Morgan tarafindan (1991) karşı karşıya gelinen engelin üstesinden gelmenin en iyi yolunu bulma olarak ifade edilmiştir. Bingham (1998) ise, belli bir hedefe ulaşmak maksadıyla karşılaşılan zorlukları yok etmeye yönelik bir dizi gayreti gerektiren süreç olarak tanımlamıştır.

Problem çözme süreci duygusal, bilişsel ve davranışsal boyutların birlikte işe koşulmasını gerektirdiği için oldukça karmaşıktır (Heppner \& Baker 1997). Bu sebeple, problem çözme süreci boyutlandırılmış, bileşenlere ayrılmış ve Sosyal Problem Çözme Modeli öne sürülmüştür (D’Zurilla \& Nezu 1990). D’Zurilla ve Nezu (1990) sosyal problem çözmeyi, “Bireyin günlük hayatta karşı karşıya geldiği problem hallerinde bu durumla etkili baş etme yolu bulmak üzere başladığı ve ürettiği bilişsel-davranışsal-duygusal bir süreç." olarak tanımlamışlardır.

Problemin ele alınış şekline bağılı olarak problemin çözümündeki başarı bireyden bireye farkl11ık göstermektedir. Kişinin problemini çözmede yetersiz kalması, çevresinde giderek artan problemler, anksiyete ve depresyon gibi sonuçlara da sebep olabilmektedir (D'zurilla \& Goldfried 1971). Sosyal problem çözme becerisi, stres, kayg1, depresyon, duygusal olarak iyi olma gibi birçok psikolojik değişken ile ilişkili olduğu gibi zayıf akademik ve iş performansı gibi değişkenlerle de ilişki içerisindedir (D'Zurilla \& Nezu 2006). Problem çözme, bireyin mutlu ve doyumlu bir hayat yaşamasına olanak veren, ruh sağlı̆̆ını koruyan önemli bir beceridir (Sonmaz 2002). Bununla birlikte, sosyal problem çözme becerisi öğrenilebilmekte ve eğitim yolu ile geliştirilebilmektedir (Eskin 2011).

Öğretmenlik mesleğinde, tüm branşlarda, problem çözme becerileri büyük öneme sahiptir. Alanda yurtdışında yapılan çalışmalara bakıldığında öğretmenlerle ve öğretmen adaylarıyla yapılmış çalışmalara rastlanmamıştır. Problem çözme becerisiyle ilgili yurtdışında yapılan çalışmalara bakıldığında travmatik beyin hasarı bulunan çocuklarla (Janusz 2002), şizofreni hastalarıyla (Revheim \& Medalia 2004), yüksek işlevli şizofreni hastalarıyla (Vaskinn et al. 2009), ergenlerle (Chang 2002), ortaokul 7. Sınıf öğrencileriyle (Shute et al. 2016), intihara meyilli psikiyatri hastalarıla (Schotte et al. 1987), hastanede yatarak tedavi gören psikiyatri hastas1 çocuklarla (Kazdin et al. 1987), hafif depresyon hastalarıyla (Gotlib et al. 1979) ve klinik depresyon hastalarıyla (Gotlib et al. 1979), karşı gelme bozukluğu olan çocuklarla (Dunn et al. 1997; Matthys et al. 1999), davranım bozukluğu olan çocuklarla (Dunn et al. 1997; Matthys et al. 1999) ve dikkat eksikliği ve hiperaktivite bozukluğu olan çocuklarla (Matthys et al. 1999) yapılmış çalışmalara rastlanmıştır.

Alanda ülkemizde gerçekleştirilen çalışmalara bakıldığında üniversite öğrencileri ile yapılan çalışmalarda, sosyal bilgiler (Aylar \& Aksin 2011; Yenice 2012), fen bilgisi (Ocak \& Eğmir 2014; Altunçekiç et al. 2005; Genç \& Kalafat 2007; Kırılmazkaya 2010; Yenice et al. 2012; Yenice 2012), sınıf öğretmenliği (Tümkaya \& İflazoğlu 2000; Ocak \& Eğmir 2014; Altunçekiç et al. 2005; Genç \& Kalafat 2007; Kırılmazkaya 2010; Aslan \& Sağır 2011; Yenice 2012), matematik (Ocak \& Eğmir 2014; Altunçekiç et al. 2005), fizik (Çalışkan et al. 2006), Türkçe (Ocak ve Eğmir 2014; Genç ve Kalafat 2007), İngilizce (Genç \& Kalafat 2007), müzik (Otacıoğlu 2007), rehberlik ve psikolojik danışmanlık (Otacığlu 2007; Karabacak et al. 2015), zihin engelliler (Karabacak et al. 2015), okul öncesi (Ocak \& Eğmir 2014; Şahin 2011; Karabacak et al. 2015), zihin engelliler ve işitme engelliler öğretmenliği dahil olmak üzere farklı alanlardaki üniversite öğrencilerinin (Kurtyılmaz 2005; Güneş 2011) problem çözme becerileriyle ilgili çalışmalarına rastlanmıştır. Öğretmenlerle yapılan çalışmalarda ise okul öncesi öğretmenlerinin (Kesgin 2006; Ceylan et al. 2012; Sesli 2013; Karaca et al. 2013) ve 
sınıf öğretmenlerinin (Serin 2006) problem çözme becerileriyle ilgili çalışmalarına rastlanmıştır. Son olarak, özel eğitim okullarında çalışan okul yöneticilerinin problem çözme becerilerini inceleyen bir çalışmaya rastlanmıştır (Yazğan 2015). Ancak özel eğitim öğretmenlerinin problem çözme becerilerini inceleyen çalışmaya rastlanmamıştır. Daha önce de belirtildiği gibi problem çözme gelişip değişebilmektedir. Bu nedenle, öğretmenlerin meslek yaşamlarında sahip oldukları becerilerin belirlenmesi önemlidir. Bu çalışmanın amacı devlet okullarında çalışan, özel eğitim bölümü mezunu özel eğitim öğretmenlerinin sosyal problem çözme düzeylerinin belirlenmesi ve cinsiyet ve çalışma yılı değişkenlerine göre incelenmesidir.

\section{Yöntem}

Gerçekleştirilen çalışma bir tarama çalışmasıdır. Tarama yöntemi, geçmişte veya halen var olan bir durumu var olduğu şekilde betimlemeyi amaçlayan araştırma yaklaşımıdır (Karasar 2000). Örneklem belirlemek için, katılıma gönüllülük gösteren ve kolay ulaşılabilen katılımcılar ile çalışma gerçekleştiği için, uygun örnekleme kullanılmıştır. Uygun örnekleme yöntemi zaman, para ve işgücü açısından var olan sınırlılıklar nedeniyle örneklemin kolay ulaşılabilir ve uygulama yapılabilir birimlerden seçilmesidir (Büyüköztürk et al. 2009). Araştırma verileri 2015 Güz döneminde, çevrimiçi olarak toplanmıştır.

\section{Katılımelar}

Araştırma katılımcılarını devlet kurumlarında görev yapan 115 özel eğitim öğretmeni oluşturmaktadır. Araştırmanın örneklem seçimi uygun örneklemedir. Araştırma evreni, araştırma katılımcıları ile sınırlıdır. Katılımcıların 67'si kadın (\%58.3) ve 48'i erkektir (\%41.7). Katılımcıların çalışma yılları incelenmiştir. Buna göre katılımcıların 93'ü 1-5 yıl arası (\%80.9) çalışma deneyimine sahipken 22'si 5 y1ldan fazla (\%19.1) çalışma deneyimine sahiptir. Katılımcıların tamamı, üniversitelerin özel eğitim bölümlerinden mezundur.

\section{Kullanılan Araçlar}

Araştırmada katılımcıların demografik bilgilerini elde etmek amacı ile araştırmacılar tarafından hazırlanan demografik form kullanılmıştır. Araştırmada, sosyal problem çözme becerileri için D' Zurilla ve diğerleri (2002) tarafından geliştirilen "Sosyal Problem Çözme Envanteri- Kısa Formu” (Social Problem Solving Inventor-Short Form) kullanılmıştır. Formun Türkçe'ye adaptasyon, geçerlilik ve güvenilirlik çalışması Çekici (2009), tarafından yapılmıştır. Sosyal Problem Çözme Envanteri- Kısa Formu (SPÇE-KF) "problem yönelimi” ve "problem çözme tarzları" olmak üzere iki boyuttan ve toplamda 5 alt ölçekten oluşmaktadır. Bununla birlikte ölçekten genel problem çözme düzeyi puanı elde edilebilmektedir (Çekici, 2009). Kullanılan form 25 maddeden oluşmaktadır. Maddeler, 0 (hiç uygun değil) ile 4 (tamamen uygun) arasında olmak üzere beşli olarak derecelendirilmektedir. Ölçme aracında tersten puanlanan maddeler bulunmamaktadır. Her bir alt ölçeğe ait toplam puan elde etmek için, o alt ölçeğe giren maddelere ait puanlar toplanmaktadır. Ölçeğin uyarlama çalışmasında dört faktör bulunmaktadır. Her bir alt ölçeğe ilişkin elde edilen iç tutarlılık katsayı değerleri, alt ölçekler için sırası ile .81, .76, .74 ve .61 olarak hesaplanmıştır.

\section{Verilerin Analizi}

Öncelikle katılımcıların demografik özellikleri için frekans ve yüzdeler kullanılmıştır. Sosyal problem çözme düzeylerine ilişkin puanlamalar belirlenmiş sonrasında istatistiki analizler gerçekleştirilmiştir. Gerçekleştirilen analizlerde, ikili karşılaştırmalarda t testi uygulanmıştır. analizlerde hata payı üst sınırı .05 olarak alınmıştır. 


\section{Bulgular}

Araştırmada öncelikle özel eğitim öğretmenlerinin genel ve alt ölçekler olmak üzere sosyal problem çözme düzeylerine yer verilmiştir. Elde edilen değerler tablo 1 de görülebilir.

Tablo 1. Sosyal Problem Çözme Puanları

\begin{tabular}{|l|c|c|c|c|c|}
\hline & N & Minimum & Maksimum & X & Ss \\
\hline Olumlu yönelim & 115 & 5,00 & 20,00 & 12,48 & 3,41 \\
\hline Olumsuz yönelim & 115 &, 00 & 16,00 & 7,13 & 3,78 \\
\hline Rasyonel problem çözme & 115 & 6,00 & 20,00 & 12,94 & 3,21 \\
\hline Dikkatsiz/dürtüsel Tarz & 115 &, 00 & 14,00 & 5,11 & 2,99 \\
\hline Kaçınma & 115 &, 00 & 16,00 & 4,24 & 3,65 \\
\hline Genel toplam & 115 & 47,00 & 96,00 & 68,94 & 10,98 \\
\hline
\end{tabular}

Araştırmadan elde edilen bulgulara göre, özel eğitim öğretmenlerinin cinsiyetlerine göre sosyal problem çözme toplam ve alt ölçek puanları için t test sonuçları tablo 2 de görülmektedir. Buna göre, özel eğitim öğretmenlerinin cinsiyete göre sosyal problem çözme genel puanları ( $\mathrm{t}=-, 337$; $\mathrm{p}>.05)$, olumlu yönelim puanları ( $\mathrm{t}=-, 572 ; \mathrm{p}>.05)$, rasyonel problem çözme puanları $(\mathrm{t}=-, 969$; $\mathrm{p}>$.05) ve dürtüsel/dikkatsiz tarz puanları $(\mathrm{t}=, 351 ; \mathrm{p}>.05)$ anlamlı fark göstermemektedir. Ancak, özel eğitim öğretmenlerinin sosyal problem çözme puanları, cinsiyete göre incelendiğinde olumsuz yönelim puanları $(\mathrm{t}=-2,794 ; \mathrm{p}<.05)$, kadın öğretmenler lehinde ve kaçınım puanları $(\mathrm{t}=2,132 ; \mathrm{p}<.05)$ erkek öğretmenler lehinde olmak üzere anlamlı fark göstermektedir. Buna göre, kadın özel eğitim öğretmenlerinin erkek özel eğitim öğretmenlerine göre daha fazla olumsuz yönelim gösterdiği ve erkek özel eğitim öğretmenlerinin de kadın meslektaşlarına göre daha fazla kaçınım gösterdiği söylenebilir.

Tablo 2. Özel Eğitim Öğretmenlerinin Cinsiyetlerine Göre Problem Çözme Puanları İçin T-Test Sonuçları

\begin{tabular}{|c|c|c|c|c|c|c|c|}
\hline & & $\mathrm{n}$ & $X$ & Ss & sd & $\mathrm{t}$ & $\mathrm{p}$ \\
\hline \multirow[t]{2}{*}{ olumlu yönelim } & Kadın & 67 & 12,64 & 3,34 & \multirow[t]{2}{*}{113} & \multirow[t]{2}{*}{,- 572} & ,568 \\
\hline & Erkek & 48 & 12,27 & 3,54 & & & \\
\hline \multirow[t]{2}{*}{ olumsuz yönelim } & Kadın & 67 & 7,94 & 3,87 & \multirow[t]{2}{*}{113} & \multirow[t]{2}{*}{$-2,794$} & ,006* \\
\hline & Erkek & 48 & 6,00 & 3,37 & & & \\
\hline \multirow[t]{2}{*}{ rasyonel problem çözme } & Kadın & 67 & 13,19 & 2,97 & \multirow[t]{2}{*}{113} & \multirow[t]{2}{*}{,- 969} & ,334 \\
\hline & Erkek & 48 & 12,60 & 3,53 & & & \\
\hline \multirow[t]{2}{*}{ dürtüsel/dikkatsiz tarz } & Kadın & 67 & 5,02 & 3,07 & \multirow[t]{2}{*}{113} & \multirow[t]{2}{*}{,351 } & ,726 \\
\hline & Erkek & 48 & 5,22 & 2,88 & & & \\
\hline \multirow[t]{2}{*}{ kaçınım } & Kadın & 67 & 3,61 & 3,17 & \multirow[t]{2}{*}{84,551} & \multirow[t]{2}{*}{2,132} & ,036* \\
\hline & Erkek & 48 & 5,12 & 4,11 & & & \\
\hline \multirow[t]{2}{*}{ Genel toplam } & Kadın & 67 & 69,25 & 9,76 & \multirow[t]{2}{*}{85,037} & \multirow[t]{2}{*}{,- 337} & ,737 \\
\hline & Erkek & 48 & 68,52 & 12,58 & & & \\
\hline
\end{tabular}

Araştırmanın bir başka bulgusu, özel eğitim öğretmenlerinin sosyal problem çözme düzeylerinin çalışma yılına göre incelenmesidir. Tablo 3 incelendiğinde, özel eğitim öğretmenlerinin çalışma yılına göre problem çözme genel $(\mathrm{t}=-, 337 ; \mathrm{p}>.05)$ ve alt ölçek puanlarının anlamlı farklılık göstermediği bulgusuna ulaşılmıştır (tablo sırası ile olumlu yönelim için $\mathrm{t}=-, 573$; $\mathrm{p}>.05$; olumsuz yönelim için $t=1,122 ; \mathrm{p}>.05$; rasyonel problem çözme için $t=-, 127 ; \quad \mathrm{p}>.05$; dürtüsel/dikkatsiz tarz için $\mathrm{t}=, 354 ; \mathrm{p}>.05$; kaçınma için $\mathrm{t}=-, 106 ; \mathrm{p}>.05$ ). 
Tablo 3. Özel Eğitim Öğretmenlerinin Çalışma Yılına Göre Problem Çözme Puanları İçin TTest Sonuçları

\begin{tabular}{|c|c|c|c|c|c|c|c|}
\hline & & $\mathrm{n}$ & $\mathrm{X}$ & Ss & sd & $\mathrm{t}$ & $\mathrm{p}$ \\
\hline \multirow{2}{*}{ olumlu yönelim } & $1-5 y_{1} 1$ & 93 & 12,39 & 3,33 & 113 & \multirow[t]{2}{*}{,- 573} &, 568 \\
\hline & 5 ve üstü & 22 & 12,86 & 3,80 & & & \\
\hline \multirow{2}{*}{ olumsuz yönelim } & $1-5 y 11$ & 93 & 7,32 & 3,68 & 113 & \multirow[t]{2}{*}{1,122} & ,264 \\
\hline & 5 ve üstü & 22 & 6,31 & 4,15 & & & \\
\hline \multirow{2}{*}{ rasyonel problem çözme } & $1-5 y_{1} 1$ & 93 & 12,92 & 2,95 & 26,027 & \multirow[t]{2}{*}{,- 127} & ,900 \\
\hline & 5 ve üstü & 22 & 13,04 & 4,23 & & & \\
\hline \multirow{2}{*}{ dürtüsel/dikkatsiz tarz } & $1-5 y 11$ & 93 & 5,16 & 2,76 & 113 & \multirow[t]{2}{*}{,354 } & ,724 \\
\hline & 5 ve üstü & 22 & 4,90 & 3,86 & & & \\
\hline \multirow{2}{*}{ kaçınım } & $1-5 y_{11}$ & 93 & 4,22 & 3,62 & 113 & \multirow[t]{2}{*}{,- 106} & ,916 \\
\hline & 5 ve üstü & 22 & 4,31 & 3,88 & & & \\
\hline \multirow{2}{*}{ Genel toplam } & $1-5 y 11$ & 93 & 68,61 & 9,93 & 25,632 & \multirow[t]{2}{*}{,- 527} & ,603 \\
\hline & 5 ve üstü & 22 & 70,36 & 14,82 & & & \\
\hline
\end{tabular}

\section{Sonuç ve Tartışma}

Araştırmada devlet okullarında çalışan, özel eğitim bölümü mezunu özel eğitim öğretmenlerinin sosyal problem çözme düzeylerinin belirlenmesi ve cinsiyet, çalışma yılı değişkenlerine göre incelenmesi amaçlanmaktadır. Araştırmadan elde edilen bulgulara göre özel eğitim öğretmenlerinin genel problem çözme düzeyleri minimum 47, maksimum 96 puan olup, ortalamaları 68,94, standart sapması ise 10,98' dir. Araştırmanın bir başka bulgusu, özel eğitim öğretmenlerinin cinsiyetlerine göre inceleme yapıldığında sosyal problem çözme düzeylerinin olumsuz yönelim alt boyutunda kadın öğretmenler lehine, kaçınma alt boyutunda ise erkek öğretmenler lehine fark bulunurken diğer alt boyutlar ve genel puanlarda anlamlı ölçüde fark bulunmamas1dır. Benzer bulgusu olan çalışmalara bakıldığında Güneş'in (2011) farklı fakültelerden üniversite öğrencileriyle yaptığı çalışmada probleme olumsuz yönelim alt boyutunda kadınların lehine anlamlı fark bulduğu ve kaçıngan yaklaşım alt boyutunda erkekler lehine anlamlı fark bulduğu görülmektedir.

Benzer bulgusu olan diğer çalışmalara bakıldığında Aylar ve Aksin'in (2011), Aslan ve Sağır'ın (2011), Demirtaş ve Dönmez'in (2008), Genç ve Kalafat'ın (2007), Görgen ve diğerlerinin (2011), Kırılmazkaya'nın (2010), Karabacak ve diğerlerinin (2015), Yenice'nin (2012), Tümkaya ve İflazoğlu'nun (2000), Aslan ve Sağır'ın (2011) ve Yenice'nin (2012) öğretmenlerle/öğretmen adaylarıyla yaptıkları çalışmalarda da cinsiyet ve problem çözme arasında anlamlı ölçüde fark bulunmamıştır. Ayrıca Ocak ve Eğmir'in (2014) çalışmasında kaçıngan yaklaşım alt boyutunda erkekler lehine bulunan anlamlı fark bu çalışmanın bulgularını desteklemektedir.

Farklı bulguları olan çalışmalara bakıldığıında; Aslan ve Sağır'ın (2011) ve Yenice'nin (2012) çalışmalarında aceleci yaklaşım alt boyutunda erkekler lehine anlamlı ölçüde fark bulunmuştur. Altunçekiç ve diğerlerinin (2005) ve Karaca ve diğerlerinin (2013) yaptıkları çalışmalarda ise genel puanlarda erkekler lehine anlamlı sonuçlar bulunmuştur. Ocak ve Eğmir'in (2014) ve Serin'in (2006) çalışmalarında da genel puanlarda kadınlar lehine anlamlı fark bulunmuştur. Ayrıca Ocak ve Eğmir'in çalışmasında (2014) aceleci yaklaşım alt boyutlarında erkekler lehine anlamlı fark bulunmuştur, Serin'in (2006) çalışmasında ise değerlendirici yaklaşım alt boyutunda kadınlar lehine anlamlı fark bulunmuştur.

Araştırmadan elde edilen son bulgu ise öğretmenlerin çalışma yıllarına göre problem çözme 
düzeylerinde fark bulunmayışıdır. Ceylan ve diğerlerinin (2012), Karaca ve diğerlerinin, Kesgin'in (2006) ve Serin'in (2006) çalışmalarında da benzer bulgulara ulaşılmıştır.

Bu araştırmanın örneklem boyutu ve örnekleme şekli sınırlılık göstermektedir. Daha sonraki araştırmalarda bu sınırlılıkların ortadan kaldırılarak araştırmanın yenilenmesi önerilebilir. Ek olarak, öğretmenlerin mezun oldukları üniversiteler, çalıştıkları okul türleri gibi çeşitli değişkenler de incelenebilir. Bunun yanında, özel eğitim öğretmenleri için sosyal problem çözme düzeylerinin arttırılmasına yönelik uygulamalı çalışmalar gerçekleştirilmesi önerilmektedir. Bu öneriye ek olarak özel eğitim öğretmenlerine yetkili kurumlarca hizmet içi eğitimler kapsamında problem çözme becerisini destekleyen eğitimler gerçekleştirilebilir.

\section{Yazarın Notu}

Çalışma 26. Özel Eğitim Kongresi’nde (Eskişehir) sunulmuştur.

\section{KAYNAKÇA}

Altunçekiç A., Yaman S. \& Koray Ö. (2005). "Öğretmen Adaylarının Öz-Yeterlik İnanç Düzeyleri ve Problem Çözme Becerileri Üzerine Bir Araştırma (Kastamonu İli Örneği)”. Kastamonu Eğitim Dergisi 13/1 (2005) 93-102.

Aslan O. \& Sağır Ş. U. (2012). "Fen ve Teknoloji Öğretmen Adaylarının Problem Çözme Becerileri”. Türk Fen Eğitimi Dergisi 9/2 (2012) 82-94.

Aylar F. \& Akşin A. (2011). "Sosyal Bilgiler Öğretmen Adaylarının Öz-Yeterlilik İnanç Düzeyleri ve Problem Çözme Becerileri Üzerine Bir Araştırma (Amasya Örneği)”. Ahi Evran Üniversitesi Eğitim Fakültesi Dergisi 12/3 (2011) 299-313.

Bingham A. (1998). Çocuklarda Problem Çözme Yeteneklerinin Geliştirilmesi. Çev. A. F. Oğuzkan. İstanbul 1998.

Büyüköztürk Ş., Kılıç E. K., Akgün Ö. E., Karadeniz Ş. \& Demirel F. (2009). Bilimsel Araştırma Yöntemleri. Ankara 2009.

Ceylan R., Bıçakçı Y. M., Aral N. \& Gürsoy F. (2012). "Okul Öncesi Eğitim Kurumunda Çalışan Öğretmenlerin Problem Çözme Becerilerinin İncelenmesi”. Trakya Üniversitesi Sosyal Bilimler Dergisi 14/1 (2012) 85-98.

Chang E. C. (2002). "Predicting Suicide Ideation in an Adolescent Population: Examining the Role of Social Problem Solving as a Moderator and a Mediator". Personality and Individual Differences 32/7 (2002) 1279-1291.

Chang E. C., D’Zurilla T. J. \& Sanna L. J. (2004). Social Problem Solving: Theory, Research and Training. Washington 2004.

Çalışkan S., Sezgin G. S. \& Erol M. (2006). "Fizik Öğretmen Adaylarının Problem Çözme Davranışlarının Değerlendirilmesi”. Hacettepe Üniversitesi Eğitim Fakültesi Dergisi 30/30 (2006)73-81.

Çekici F. (2009). Problem Çözme Terapisine Dayalı Beceri Geliştirme Grubunun Üniversite Öğrencilerinin Sosyal Problem Çözme Becerileri, Öfkeyle İlişkili Davranış ve Düşünceler ile Sürekli Kaygı Düzeylerine Etkisi. Yayımlanmamış Doktora Tezi. Çukurova Üniversitesi. Adana 2009.

Dunn S. E., Lochman J. E. \& Colder C. R. (1997). "Social Problem-Solving Skills in Boys With Conduct and Oppositional Defiant Disorders”. Aggressive Behavior 23/6 (1997) 457-469.

D’Zurilla T. J. \& Goldfried M. R. (1971). "Problem Solving and Behavior Modification”. Journal of Abnormal Psychology 78/1 (1971) 197-226.

D’Zurilla T. J. \& Nezu A. M. (1990). "Development and Preliminary Evaluation of The Social ProblemSolving Inventory”. Psychological Assessment 2/2 (1990) 156-163.

D’Zurilla T. J. \& Nezu A. M. (2006). Solving Life's Problems: A 5-Step Guide To Enhanced Well-Being. New York 2006. 
Eskin M. (2011). Sorun Çözme Terapisi. Ankara 2011.

Gelbal S. (1991). Problem Çözme Becerisinin Öğretimle Geliştirilmesi. Eğitimde Araylşlar 1. Sempozyumu, Eğitimde Nitelik Geliştirme. İstanbul 1991.

Genç S. Z. \& Kalafat T. (2007). “Öğretmen Adaylarının Demokratik Tutumları ile Problem”. Pamukkale Üniversitesi Eğitim Fakültesi Dergisi 22/22 (2007) 10-22.

Gotlib I. H. \& Asarnow R. F. (1979). "Interpersonal and Impersonal Problem-Solving Skills in Mildly and Clinically Depressed University Students”. Journal of Consulting and Clinical Psychology 47/1 (1979) 86-95.

Heppner P. P. \& Baker C. E. (1997). “Aplications of the Problem Solving Inventory”. Measurement and Evaluation in Counseling and Development 29/4 (1997) 229-242.

Heppner P. P., Witty T. E. \& Dixon W. A. (2004). "Problem-Solving Appraisal and Human Adjustment: A Review of 20 Years of Research Using the Problem Solving Inventory”. The Counseling Psychologist 32/3 (2004) 344-428.

Janusz J. A., Kirkwood M. W., Yeates K. O. \& Taylor H. G. (2002). “Social Problem-Solving Skills in Children with Traumatic Brain Injury: Long-Term Outcomes and Prediction of Social Competence”. Child Neuropsychology 8/3 (2002) 179-194.

Karabacak K., Nalbant D. \& Topçuoğlu P. (2015). “Examination of Teacher Candidates’ Problem Solving Skills According to Several Variables”. Procedia-Social and Behavioral Sciences 174 (2015) 3063-3071.

Karaca N. H., Aral N. \& Karaca L. (2013). “Okul Öncesi Öğretmenlerinin Problem Çözme Becerisi ve Benlik Saygısının İncelenmesi”. Ĕgitim ve Öğretim Araştırmaları Dergisi 2/3 (2013) 67-74.

Karasar N. (2000). Bilimsel Araştırma Yöntemleri. Ankara 2000.

Kazdin A. E., Esveldt-Dawson K., French N. H. \& Unis A. S. (1987). "Problem-Solving Skills Training and Relationship Therapy in the Treatment of Antisocial Child Behavior”. Journal of Consulting and Clinical Psychology 55/1 (1987) 76-85.

Kesgin E. (2006). Okul Öncesi Eğitim Öğretmenlerinin Öz-Yeterlilik Düzeyleri ile Problem Çözme Yaklaşımlarını Kullanma Düzeyleri Arasındaki İlişkinin Incelenmesi (Denizli İli Örneği). Yayımlanmamış Yüksek Lisans Tezi. Pamukkale Üniversitesi. Denizli 2006.

Kırılmazkaya G. (2010). İlköğretim Fen Bilgisi ve Sınıf Öğretmen Adaylarının Problem Çözme Becerileri ve Sosyal Becerilerinin Karşılaştırılması. Yayımlanmamış Yüksek Lisans Tezi. Fırat Üniversitesi. Elazı̆̆ 2010.

Kurtyılmaz Y. (2005). Öğretmen Adaylarının Saldırganlık Düzeyleri ile Akademik Başarıları, İletişim ve Problem Çözme Becerileri Arasındaki Illişkiler: (Anadolu Üniversitesi ve Osmangazi Üniversitesi Öğrencileri Üzerinde Bir Araştırma). Yayımlanmamış Yüksek Lisans Tezi. Anadolu Üniversitesi. Eskişehir 2005.

Matthys W., Cuperus J. M. \& Van Engeland H. (1999). "Deficient Social Problem-Solving in Boys with ODD/CD, with ADHD, and with Both Disorders”. Journal of the American Academy of Child \& Adolescent Psychiatry 38/3 (1999) 311-321.

Morgan C. T. (1991). Psikolojiye Giriş. Ankara 1991.

Ocak G. \& Eğmir E. (2014). "Öğretmen Adaylarının Problem Çözme Becerilerinin Çeşitli Değişkenler Açısından İncelenmesi”. E-AJI (Asian Journal of Instruction) 2/1 (2014) 27-45.

Otacıŏlu S. G. (2007). "Eğitim Fakültelerinin Farklı Branşlarında Eğitim Alan Öğrencilerin Problem Çözme Beceri Düzeylerinin Karşılaştırılması”. Eurasian Journal of Educational Research (EJER) 29 (2007) 73-83.

Revheim N. \& Medalia A. (2004). "Verbal Memory, Problem-Solving Skills and Community Status in Schizophrenia”. Schizophrenia Research 68/2 (2004) 149-158.

Serin O. (2006). "Sınıf Öğretmenlerinin Problem Çözme Becerilerinin Çeşitli Değişkenler Açısından İncelenmesi”. Ĕ̌itim Bilim Dergisi 31/142 (2006) 80-88.

Sesli Ş. (2013). Okul Öncesi Öğretmenlerinin Problem Çözme Becerileri İle Disiplin Anlayışlarının Incelenmesi. Yayımlanmamış Yüksek Lisans Tezi. Erciyes Üniversitesi. Kayseri 2013.

Schotte D. E. \& Clum G. A. (1987). “Problem-Solving Skills in Suicidal Psychiatric Patients”. Journal of 
Consulting and Clinical Psychology 55/1 (1987) 49-54.

Shute V. J., Wang L., Greiff S., Zhao W. \& Moore G. (2016). "Measuring Problem Solving Skills via Stealth Assessment in an Engaging Video Game”. Computers in Human Behavior 63 (2016) 106-117.

Sonmaz S. (2002). Problem Çözme Becerisi İle Yaratıcılık ve Zeka Arasındaki İlişkinin İncelenmesi. Yüksek Lisans Tezi. Marmara Üniversitesi. İstanbul 2002.

Şahin D. (2011). "Pre-Schoolers, Pre-School Teachers, and Interpersonal Problem-Solving Skills: A Comparative Study in Turkey and Belgium”. Education 3-13 39/3 (2011) 305-316.

Tümkaya S. \& İflazoğlu U. A. (2000). "Ç.Ü. Sınıf Öğretmenliği Öğrencilerinin Otomatik Düşünce ve Problem Çözme Düzeylerinin Bazı Sosyo Demografik Değişkenlere Göre İncelenmesi”. Çukurova Üniversitesi Sosyal Bilimler Enstitüsü Dergisi 6/6 (2000) 143-158.

Vaskinn A., Sundet K., Hultman C. M., Friis S. \& Andreassen O. A. (2009). "Social Problem-Solving in High-Functioning Schizophrenia: Specific Deficits in Sending Skills". Psychiatry Research 165/3 (2009) 215-223.

Yazğan F. (2015). Özel Eğitim Okullarındaki Okul Yöneticilerinin Problem Çözme Becerilerinin İncelenmesi. Yayınlanmamış Yüksek Lisans Tezi. İstanbul Aydın Üniversitesi. İstanbul 2015.

Yenice N. (2012). "Öğretmen Adaylarının Öz-Yeterlik Düzeyleri İle Problem Çözme Becerilerinin İncelenmesi”. Elektronik Sosyal Bilimler Dergisi 11/39 (2012) 36-58.

Yenice N., Özden B. \& Evren B. (2012). "Examining of Problem Solving Skills According to Different Variables for Science Teachers Candidates”. Procedia-Social and Behavioral Sciences 46 (2012) 3880-3884. 